\title{
Tropical Clayey Sand Soil's Behaviour Analysis and Its Empirical Correlations via Geophysics Electrical Resistivity Method and Engineering Soil Characterizations
}

\author{
Andy Anderson Bery, Rosli Saad \\ Geophysics Section, School of Physics, Universiti Sains Malaysia, Penang, Malaysia \\ Email: andersonbery@yahoo.com.my
}

Received July 12, 2011; revised September 9, 2011; accepted November 3, 2011

\begin{abstract}
Soil is a heterogeneous medium which consist of liquid, solid, and gaseous phases. The solid and liquid phases play an essential role in soil spontaneous electrical phenomena and in behaviour of electrical fields, artificially created in soil. Soil electrical properties are the parameters of natural and artificially created electrical fields in soils and influenced by distribution of mobile electrical charges, mostly inorganic ions, in soils. Geophysical method of electrical resistivity was used for measuring soil electrical properties and tested in different soil studies. Laboratory tests were performed for the numbers of clayey sandy soil samples taken from Batu Uban area. The empirical correlations between electrical parameter, percentage of liquid limit, plastic limit, plasticity index, moisture content and effective soil cohesion were obtained via curvilinear models. The ranges of the soil samples are changed between $229 \Omega \mathrm{m}$ to $927 \Omega \mathrm{m}$ for resistivity $(\rho), 6.01 \mathrm{kN} / \mathrm{m}^{2}$ to $14.27 \mathrm{kN} / \mathrm{m}^{2}$ for effective soil cohesion $\left(C^{\prime}\right), 35.08 \mathrm{kN} / \mathrm{m}^{2}$ to $51.47 \mathrm{kN} / \mathrm{m}^{2}$ for internal fiction angle (Ø), $38 \%$ to $88 \%$ for moisture content $(W), 33 \%$ to $78 \%$ for liquid limit $\left(W_{L}\right), 21 \%$ to $43 \%$ for plastic limit $\left(W_{p}\right)$ and $11 \%$ to $35 \%$ for plasticity index $(P I)$. These empirical correlations model developed in this study provides a very useful tool to relate electrical resistivity with effective cohesion, internal friction angle (strength), void ratio, porosity, degree of saturation, moisture content, liquid limit, plastic limit and plasticity index in context of medium-grained of clayey sandy soil that is, its fluid behaviours.
\end{abstract}

Keywords: Empirical Correlations; Regression Coefficient; Resistivity; Moisture Content; Fluid Behaviours

\section{Introduction}

Natural geomaterials whose skeletons form the primary structure to supports loadings consists of various solid mineral particles with diverse size, shape and arrangement, while multiple phases of pore fluids fill in their voids, such as air, water and solutions [1]. Many kinds of electrical fields and potentials are often simultaneously observed in natural soil; thus, it is difficult to know what mechanism is responsible for their formation. Electrical conductivity and resistivity of soils have been investigated in a large number of studies, which can be divided into three groups. The first group includes laboratory studies of electrical conductivity and dielectric constant of different dispersed media (including soils) with electromagnetic waves $[1,2]$. These studies help to develop relationship between electrical parameters, quantitative and qualitative compositions of electrolytic solutions [2]. The relationships were enhanced by the studies of soil electrical parameters with constant electrical field. For some diluted soil solutions and groundwater, the methods are developed to calculate electrical conductivity from the solution compositions. Electrical conductivity of the extracted soil solutions have been studied vigorously [3]. The second group of studies is devoted to laboratory measurements of surface electrical conductivity. The surface electrical conductivity is a major parameter describing structure of electrical double layer and its ion composition. There is only limited special research with experimental measurements of surface electrical conductivity in soils [4]. The third group of studies includes measurements of electrical conductivity of soils, rocks, and sediments in situ with various geophysical methods $[4,5]$.

In the general engineering sense, soils defined as the uncemented aggregate of mineral grains and decayed organic matter (solid particles) along with the liquid and gas that occupy the empty space between the solid particles. Soil is used as a construction material in various engineering projects, and it supports structural foundations [6]. Thus civil engineers must study the properties of soil such as its origin, grain-size distribution, ability to drain water, shear strength, compressibility and so on. The insitu behaviour of soils is complex because it is heavily 
dependent upon numerous factors. To acquire appropriate understanding, it is necessary to analyze them not only through geophysics and geotechnical engineering skills but also through other associated disciplines like geology, geomorphology, climatology and other earth and atmosphere related sciences [7]. It is understood that geotechnical problems with socio-economic impacts like landslides can be addressed within a framework that accounts for behavioural features in natural soils [7]. Research is actively taking place in many countries, each focusing on natural deposits of local importance, and a unified framework that can account for all important effects is still being developed [6,7]. Although the development of this unified framework requires a huge and joint effort from as many sources as possible, by means of the best of their academic and technical skills and using best possible equipments.

In this study, the clayey sand behaviour was estimated through the analysis of their engineering characterizations. The objective of this study intents the empirical correlations between soil's electrical resistivity $(\rho)$, effective soil cohesion $\left(C^{\prime}\right)$, moisture content $(W)$, void ratio $(e)$, porosity $(n)$, degree of saturation $(S)$, liquid limit $\left(W_{L}\right)$, plastic limit $\left(W_{P}\right)$ and plasticity index $(P I)$ in context of medium-grained clayey sandy soils. Prior of that, the analysis was conducted to develop practically applicable of empirical correlations to study the role of water in geosciences perspective.

\section{Geography and Geology of Penang Island}

Penang is the second smallest and one of the 13 states of Peninsular Malaysia. It is situated in the northern region and constituted by two geographically different entitiesan island (area: $293 \mathrm{~km}^{2}$ ) called Penang Island and a portion of mainland called Seberang Perai (area $738 \mathrm{~km}^{2}$ ) connected, besides a regular ferry service, through a $13.5 \mathrm{~km}$ long Bridge. The island is located between latitudes $5^{\circ} 8^{\prime} \mathrm{N}$ and $5^{\circ} 35^{\prime} \mathrm{N}$ and longitudes $100^{\circ} 8^{\prime} \mathrm{E}$ and $100^{\circ} 32^{\prime} \mathrm{E}$.

The climate is tropical with the average mean daily temperature about $27^{\circ} \mathrm{C}$ and mean daily maximum and minimum temperature ranging between $31.4^{\circ} \mathrm{C}$ and $23.5^{\circ} \mathrm{C}$ respectively. However, the individual extremes are $35.7^{\circ} \mathrm{C}$ and $23.5^{\circ} \mathrm{C}$ respectively. The mean daily humidity varies between $60.9 \%$ and $96.8 \%$. The average annual rainfall is about $267 \mathrm{~cm}$ and can be as high as $325 \mathrm{~cm}$. The two rainy seasons are south-west monsoons from April to October and north-east monsoons from October to February. The terrain consists of coastal plains, hills and mountains. There are large forest cover and the population concentration on the eastern half of the Penang Island. There are three main geological formations in Penang and their distribution is as given in Figure 1.
The major portion of Penang Island is underlain by igneous rocks. All igneous rocks are granites in terms of Streckeisen classification [8]. These granites can be classified on the basis of proportions of alkali feldspar to total feldspars. On this basis granites of Penang Island are further divided into two main groups: the North Penang Pluton approximately north of latitude $5^{\circ} 23^{\prime}$ and the South Penang Pluton. In the northern part of the island, the alkali feldspars that generally do not exhibit distinct cross-hatched twining are orthoclase to intermediate microcline in composition. In the southern region, they generally exhibit well-developed cross-hatched twining and are believed to be microcline. The North Penang Pluton has been divided into Feringgi Granite, Tanjung Bungah Granite and Muka Head micro granite. The South Penang Pluton has been divided into Batu Maung Granite and Sungai Ara Granite.

\section{Data Acquisition and Methods}

In geophysics, electrical resistivity of any material is defined as the electrical resistance of a soil sample with a cross section of unit area and with unit length as shown in Equation (1). In most earth materials, porosity and chemical content of water filling the pore spaces are more important in governing resistivity than is the conductivity of mineral grains of which the material itself is composed $[9,10]$. In this study, the electrical resistivity is measured by using soil box for 32 numbers of clayey sandy soil samples by using SCIP tester model TDLV equipment. Mathematically;

$$
R=\frac{\rho \cdot L}{A}
$$

where:

$\rho=$ Resistivity of the conductor material $(\Omega \mathrm{m})$

$L=$ Length of the conductor (m)

$A=$ Cross-sectional area $\left(\mathrm{m}^{2}\right)$

On the other hand, in geotechnical engineering, water content (Equation (2)) determination is a routine laboratory test to determine the amount of water present in a quantity of soil in terms of its dry mass [10]. As a definition,

$$
W=\frac{M_{\text {water }}}{M_{\text {solid }}} \times 100 \%
$$

where:

$M_{\text {water }}=$ water mass present in soil mass $(\mathrm{g})$

$M_{\text {solid }}=$ mass of soil solids ( $(\mathrm{g})$.

In the early 1900 s, a Swedish scientist named Battenberg developed a method to describe the consistency of fine grained soils with varying moisture contents. According to $[11,12]$, at very low moisture content, soil behaves more like a solid. When the moisture content is very high, the soil and water may flow like a liquid. Hence, on an arbitrary basic, depending on the moisture content, the 


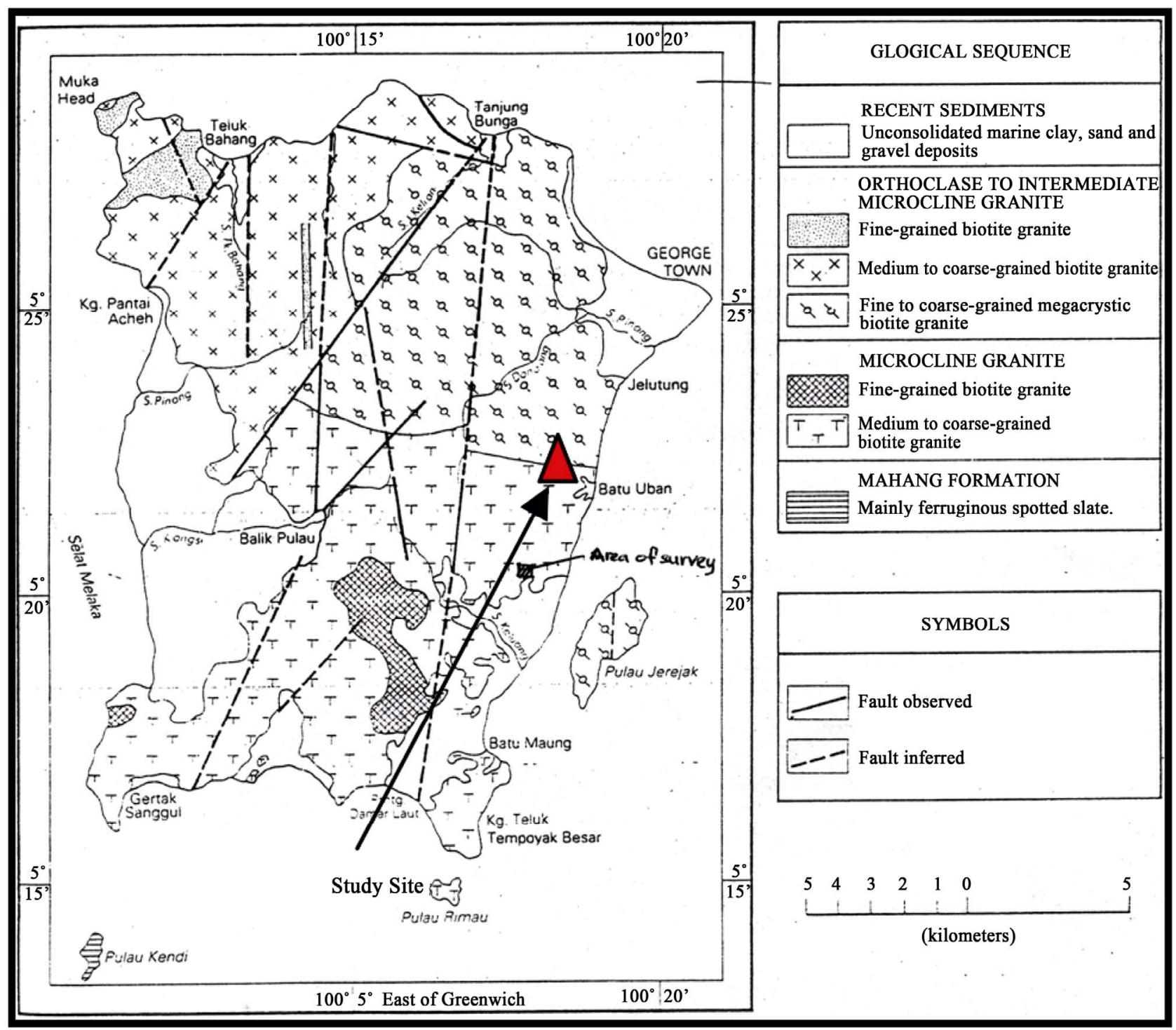

Figure 1. Geological map of Penang Island.

behaviour of soil can be divided into four basic statessolid, semisolid, plastic and liquid. The moisture content at the point of transition from semisolid to plastic state is the plastic limit and from plastic to liquid state is the liquid limit. These parameters are known as atterberg limits.

Equation (3) show the relationship of another property which is derived from the liquid limit and the plastic limit which is very useful. The property is called plasticity index and is designated as $P I$ and computed as

$$
P I=W_{L}-W_{P}
$$

where:

$W_{L}=$ Liquid limit of soil ( $\left.\%\right)$

$W_{p}=$ Plastic limit of soil (\%)

Another property can be determined from these parameters is liquidity index and is designated as LI (Equation (4)) and computed as

$$
L I=\frac{W-W_{P}}{P I}
$$

where:

$W_{p}=$ Plastic limit of soil ( $\left.\%\right)$

$W=$ Moisture content of soil (\%)

$P I=$ Plasticity index of soil (\%)

The residual soils are generally found in unsaturated condition. The shear strength of unsaturated soils can be represented by the so called extended Mohr-Coulomb criterion.

$$
\tau_{f f}=C^{\prime}+\left(\sigma-u_{a}\right) \tan \left(\varphi^{\prime \prime}\right)+\left(u_{a}-u_{w}\right) \tan \varphi_{b}
$$

$\tau_{f f}=$ shear stress on the failure plane at failure; $\mathrm{C}^{\prime}=$ effective cohesion; $\sigma=$ normal stress; $u_{a}=$ pore-air pressure; $\left(\sigma-u_{a}\right)=$ net normal stress; $\varphi^{\prime \prime}=$ effective angle of shear resistance; $u_{w}=$ pore-water pressure; 
$\left(u_{a}-u_{w}\right)=$ matrix suction; and $\varphi_{b}=$ angle indicating the rate of increase in shear strength relative to matrix suction. As the soil approaches saturation, the pore pressure, $u_{w}$, approaches the pore pressure, $u_{a}$ and Equation (5) becomes:

$$
\tau_{f f}=C^{\prime}+\left(\sigma-u_{w}\right) \tan \varphi
$$

that is the Mohr-Coulomb strength criterion for saturated soils. In applying Equation (5) to unsaturated soils, the shear strength component due to matrix suction.

$\left(u_{a}-u_{w}\right) \tan \varphi_{b}{ }^{\prime}$, is masked as the cohesion intercept, $C\left(=C^{\prime}+\left(u_{a}-u_{w}\right) \tan \varphi_{b}\right)$. Therefore, the cohesion intercept, $C$, in residual soils appear to vary widely [12].

These useful indicators are important in determine their changes in fixed study period in purpose to obtained details reliable data. All the engineering index properties obtained are useful to indicate the clayey sand's behaveiour and their empirical correlations in 5 months of fixed period.

\section{Soil's Behaviour Results}

Laboratory tests were performed to determine 32 clayey sand soils's engineering characterization during five months period. The percentages of liquid limit, plastic limit and plasticity index of the samples taken from the site are plotted against resistivity and moisture content. Note that, the resistivity of the soil samples increase with the decreasing of the moisture content percentage. Figure 2 shows the correlation of the resistivity and the moisture content of the clayey sandy soil is $\rho=1409.0 e^{-0.01(W)}$ and regression coefficient, $\mathrm{R}^{2}$ was approximately 0.504 .

For the empirical correlation between resistivity and internal friction angle, $\varphi^{\prime}$ for undisturbed clayey sand soils is $\rho=1378.0 e^{-0.03\left(\varphi^{\prime}\right)}$ and the regression coefficient, $R^{2}$ was approximately 0.647 as shown in Figure 3. It shows that internal friction angle is inversely proportional to the resistivity of samples.

In Figure 4, the empirical correlation between resistivity, $\rho$ and undisturbed soil's effective cohesion, $\mathrm{C}^{\prime}$ for

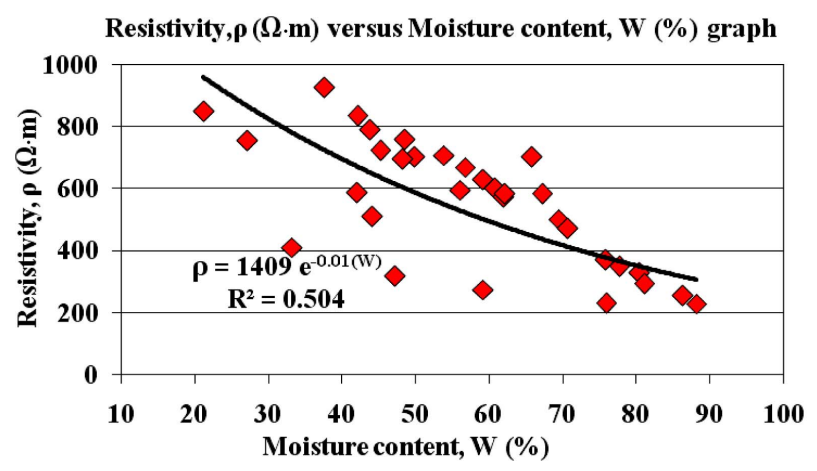

Figure 2. Empirical correlation of resistivity, $(\rho)$ and moisture content, $(W)$ of 32 clayey sand soil samples.

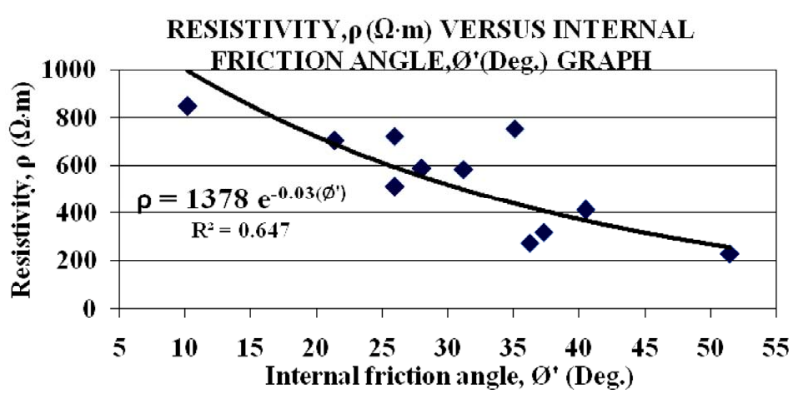

Figure 3. The empirical correlation between resistivity, $(\rho)$ and internal friction angle, $\phi^{\prime}$ of undisturbed clayey sand soil samples.

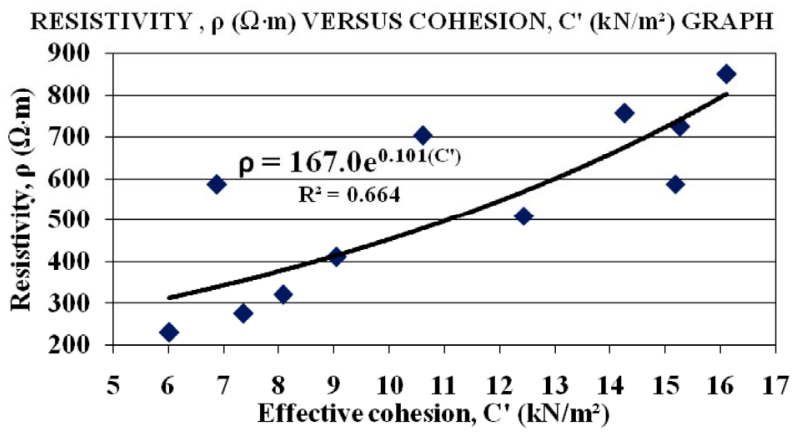

Figure 4. The empirical correlation between resistivity, $(\rho)$ and effective cohesion, $C^{\prime}$ of undisturbed clayey sand soil samples.

clayey sand soils is found as: $\rho=167.0 e^{0.101\left(C^{\prime}\right)}$ and regression coefficient, $R^{2}$ was approximately 0.664 .

Meanwhile, Figure 5 shows the empirical correlations of void ratio, porosity and degree of saturation with resistivity of clayey sand soil samples. The empirical correlation between resistivity, $\rho$ and void ratio, $e$ is, $e=-0.047 \rho+103.0$ and its regression coefficient, $R^{2}$ was approximately 0.345 . The empirical correlation between resistivity with porosity, $n$ is, $n=-0.014 \rho+51.20$ and its regression coefficient, $R^{2}$ was approximately 0.220 . However, the empirical correlation between resistivity, $\rho$ and saturation degree, $S$ is, $S=-0.048 \rho+102.7$ and its regression coefficient, $R^{2}$ was approximately 0.529 .

Figure 6 shows the empirical correlations between moisture content with void ratio, porosity and degree of saturation of clayey sand. The empirical correlation between moisture content, $W$ and void ratio, $e$ is, $e=0.845 \mathrm{~W}+36.63$ and its regression coefficient, $R^{2}$ was approximately 0.692 . The empirical correlation between moisture content, $W$ with porosity, $n$ is, $n=0.317 W+28.41$ and its regression coefficient, $R^{2}$ was approximately 0.724 . However, the empirical correlation between moisture content, $W$ and saturation degree, $S$ is, $S=0.629 W+46.30$ and its regression coefficient, $R^{2}$ was approximately 0.570 .

Figure 7 shows the empirical correlation between liquid limit, $W_{L}$ and resistivity, $\rho$ is found as: 


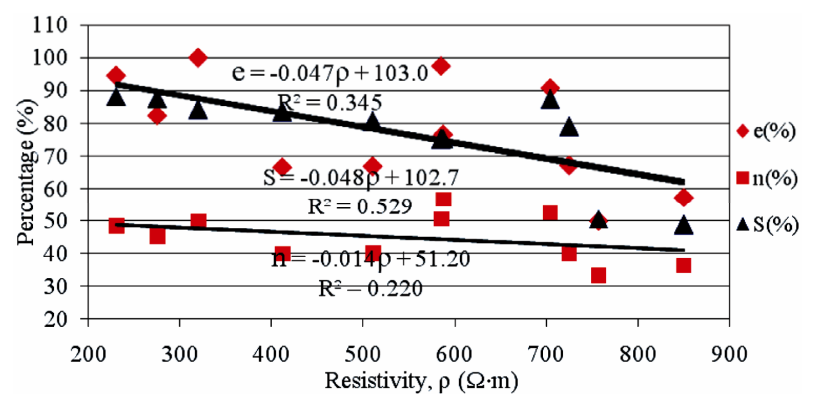

Figure 5. The empirical correlation of void ratio, $(e)$, porosity, $(n)$ and degree of saturation $(S)$ with resistivity, $(\rho)$ of clayey sand soil samples.

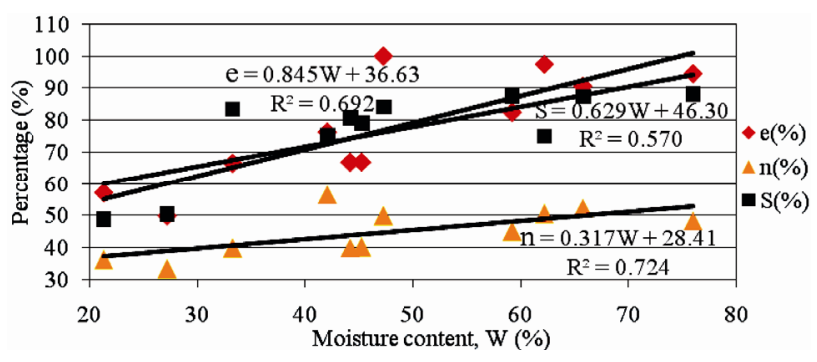

Figure 6. The empirical correlation of moisture content $(W)$ with void ratio, $(e)$, porosity, $(n)$ and saturation degree, $(S)$ of clayey sand soil samples.

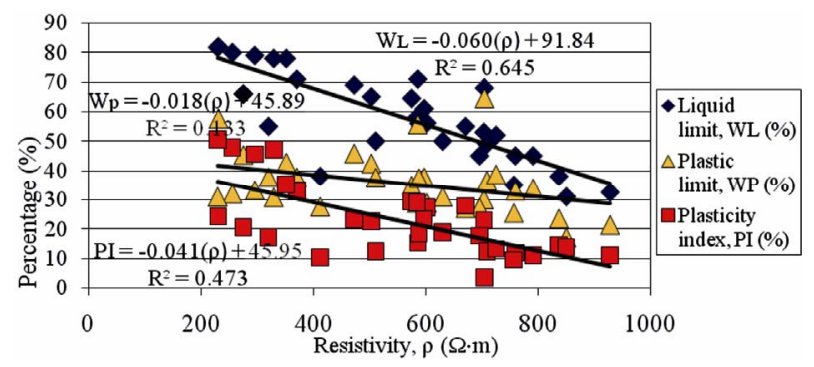

Figure 7. The empirical correlation between liquid limit, $\left(W_{L}\right)$, plastic limit, $\left(W_{p}\right)$, and plasticity index, $(P I)$ with resistivity, $(\rho)$ of 32 clayey sand soil samples.

$W_{L}=-0.060(\rho)+91.84 \mathrm{~d}$ its regression coefficient, $\mathrm{R}^{2}$ was approximately 0.645 . Then, the empirical correlation between plastic limit, $W_{p}$ and resistivity, $\rho$ is found as: $W_{p}=-0.018(\rho)+45.89$ and its regression coefficient, $\mathrm{R}^{2}$ was approximately 0.133 . Meanwhile, the empirical correlation between plasticity index, $P I$ and resistivity, $\rho$ is found as: $P I=-0.041(\rho)+45.95$ and its regression coefficient, $R^{2}$ was approximately 0.473 . It shows that all these three parameters are inversely proportional to its resistivity.

A part from that, the variation between resistivity, $\rho$ and liquidity index, $L I$ of 32 clayey sand soil samples are shown in Figure 8.

Meanwhile, Figure 9 shows the empirical correlation between liquid limit, $W_{L}$ and moisture content, $W$ of 32 clayey sand soil is found as: $W_{L}=0.829(W)+10.35$ and its regression coefficient, $R^{2}$ was approximately 0.876 . The empirical correlation between plastic limit, $W_{p}$ and moisture content, $\mathrm{W}$ of clayey sand soil samples is found as: $W_{p}=0.258(W)+20.60$ and its regression coefficient, $R^{2}$ was approximately 0.186 . Meanwhile, the empirical correlation between plasticity index, $P I$ and moisture content, $W$ of clayey sand soil samples is $P I=0.571 W+10.25$ and its regression coefficient, $\mathrm{R}^{2}$ was approximately 0.637 . It shows that the parameters are directly proportional to its resistivity values.

Figure 10 shows empirical correlation between moisture content, $\mathrm{W}$ and liquidity index, $L I$ of clayey sand soil is found as: $L I=0.891(W)+39.20$ and its regression coefficient, $R^{2}$ was approximately 0.164 .

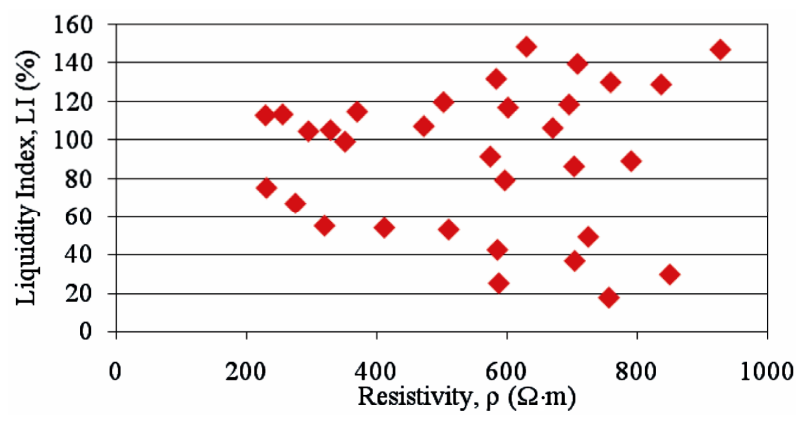

Figure 8. The variation between liquidity index, $(L I)$ with resistivity, $(\rho)$ of 32 clayey sand soil samples.

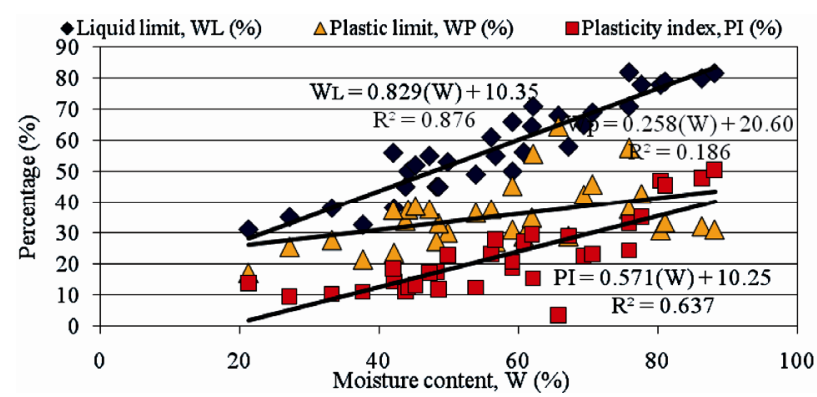

Figure 9. The empirical correlation between liquid limit, $\left(W_{L}\right)$, plastic limit, $\left(W_{p}\right)$, and plasticity index, $(P I)$ with moisture content, $(W)$ of 32 clayey sand soil samples.

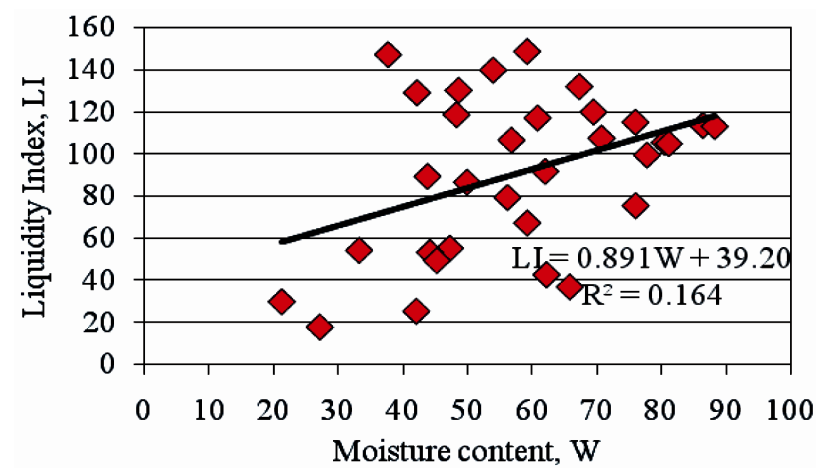

Figure 10. The variation between liquidity index, $(L I)$ and moisture content, $(W)$ of clayey sand soil samples. 


\section{Conclusions and Recommendation}

Soil behaviour of clayey sand soils study is difficult and challenging study especially for monitoring and investigative techniques. In this research, technical techniques were used in purpose of investigate the physical characterizations of study area. The integrated study of the physical environment with engineering laboratory practices for soil samples collected from the investigated area is succeed in reaching the objectives of this research.

Generally, after analyzing the data obtained collectively from 32 samples of clayey sand soil within five months monitoring period located on Batu Uban area of Penang Island, the following conclusions and recommendations are made.

- The cohesion $\left(C^{\prime}\right)$ of clayey sand soils can influence the resistivity values of tropical clayey sandy soils. The higher the resistivity values, the higher of effecttive cohesion values which associated with their density and compression.

- The moisture content can influence the soil's strength and resistivity values. The present of moisture content can reduce the soil's strength $\left(\varnothing^{\prime}\right)$ by lose its soil particles chain and it also able to increase the soil's conductivity.

- Shear strength of this soil is determined by the angularity of the sand particles and moisture content.

- The moisture content significantly modifies their strength $\left(\varnothing^{\prime}\right)$. As moisture increase, strength decreases. This is because increasing moisture content cause greater separation of soil particles and further, causes softening of soil cements.

- The empirical correlations models in this study are successfully determine to show strong correlations with granitic residual soils of Batu Uban area which significant to tropical clayey sand soil's behaviour.

\section{Acknowledgements}

Special thanks are due to Prof. Dr. Fauziah Ahmad who gave permission to use the Direct Shear Test equipment in USM Engineering Campus, Penang. The author also wishes thank to Assoc. Prof. Siti Noor Linda Taib from UNIMAS, Sarawak, Malaysia. Lastly, I wished thanks to Ms. Eva Diana and Mr. Jeff Steven.

\section{REFERENCES}

[1] J. E. Bowles, "Engineering Properties of Soils and Their Measurements," McGraw Hill Publication, New York, 1992.

[2] X. Dong, "Characterization of Soil Behavior Using Electromagnetic Wave-Based Technique," Unpublished Ph.D. Thesis, Hong Kong University of Science and Technology, 2006.

[3] H. Rahardjo, E. C. Leong and S. K. Tang, "Characterisation and Engineering Properties of Singapore Residual Soils," Proceeding of Specialty Workshop on Characterisation and Engineering Properties of Natural Soils, Singapore, 2-4 December 2003, pp. 1279-1304.

[4] T. T. Soon and K. K. Phoon, "Preface," Proceeding of Specialty Workshop on Characterisation and Engineering Properties of Natural Soils, Singapore, 2-4 December 2003, pp. IX-X.

[5] E. F. Bergman and T. L. McKnight, "Introduction to Geography," Prentice Hall, Englewood Cliffs, 2000, pp. 7379.

[6] M. B. Dobrin and C. H. Savit, "Introduction to Geophysical Prospecting," McGraw Hill, New York, 1988.

[7] A. A. Bery, R. Saad, N. M. Mustaza, N. A. Ismail, N. El Hidayah Ismail and E. Tonnizam, "Slope Stability Analysis via Soil's Geotechnical Properties and Its Geophysical Characterizations," National Geoscience Conference, Malaysia, 11-12 June 2011, p. 158.

[8] A. L. Streckeisen, "Classification and Nomenclature of Igneous Rocks," Neues Jahrbuch für Mineralogie (Abhandlungen), Vol. 107, No. 2-3, 1969, pp. 144-240.

[9] L. A. Pozdnyakova, A. I. Pozdnyakov and L. O. Karpachevsky, "Study Hydrology of Valley Agricultural Landscapes with Electrical Resistance Methods," Proceeding of XXI Assembly of European Geophysical Society, HS16 "The Hydrology of Small Agricultural Catchments", Hague, 1996, pp. 341-352.

[10] J. M. Reynolds, "An Introduction to Applied and Environmental Geophysics," John Willey \& Sons Ltd., New York, 1997.

[11] R. E. Hunt, "Geotechnical Engineering Investigation Handbook," 2nd Edition, Taylor and Francis Group, Boca Rotan, 2005.

[12] M. D. Braja, "Fundamental of Geotechnical Engineering," Brooks/Cole Publishing Company, Belmont, 2000. 